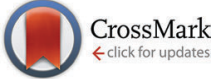

Cite this: Chem. Commun., 2016, 52,4207

Received 31st January 2016 Accepted 22nd February 2016

DOI: $10.1039 / \mathrm{c} 6 \mathrm{cc} 00972 \mathrm{~g}$

www.rsc.org/chemcomm

\section{Chiral-at-metal iridium complex for efficient enantioselective transfer hydrogenation of ketones†}

\author{
Cheng Tian, ${ }^{a}$ Lei Gong ${ }^{\star a}$ and Eric Meggers ${ }^{\star a b}$
}

\begin{abstract}
A bis-cyclometalated iridium(III) complex with metal-centered chirality catalyzes the enantioselective transfer hydrogenation of ketones with high enantioselectivities at low catalyst loadings down to $0.002 \mathrm{~mol} \%$. Importantly, the rate of catalysis and enantioselectivity are markedly improved in the presence of a pyrazole co-ligand. The reaction is proposed to proceed via an iridium-hydride intermediate exploiting metal-ligand cooperativity (bifunctional catalysis).
\end{abstract}

Transition metal catalyzed asymmetric transfer hydrogenation (ATH) has developed into a popular method for the generation of non-racemic chiral alcohols and amines using isopropanol, formic acid/triethylamine or sodium formate as convenient and inexpensive hydrogen sources. ${ }^{1}$ Since Noyori's seminal discovery of highly enantioselective ATH catalysts based on ruthenium(II) half sandwich complexes containing monotosylated 1,2-diamines, ${ }^{2}$ transition metals such as $\mathrm{Ru}(\mathrm{II}),{ }^{3} \mathrm{Os}(\mathrm{II}),{ }^{4} \mathrm{Ir}(\mathrm{III}),{ }^{5} \mathrm{Rh}(\mathrm{III}),{ }^{6}$ and $\mathrm{Fe}(\mathrm{II})^{7}$ have been combined with a large variety of different chiral ligands to achieve high turnover numbers (TON) and turnover frequencies (TOF) for different substrate classes. ${ }^{8}$ Here we report a unique catalyst that relies on metal-centered chirality using exclusively achiral ligands. ${ }^{9}$

We recently developed a novel class of chiral Lewis acid catalysts based on octahedral chiral-only-at-metal iridium(III) and rhodium(III) complexes, in which the octahedral metal center is coordinated irreversibly by two cyclometalating bidentate ligands in a propeller-type fashion, complemented by two exchangelabile acetonitriles. ${ }^{10-17}$ In these catalysts, metal-centered chirality (metal centrochirality) is the only source of chirality. We were wondering if such complexes are suitable for catalyzing ATH and we used the reduction of acetophenone as our initial model reaction (1a $\rightarrow$ 2a, Fig. 1).

\footnotetext{
${ }^{a}$ College of Chemistry and Chemical Engineering, Xiamen University,

Xiamen 361005, People's Republic of China. E-mail: gongl@xmu.edu.cn, meggers@chemie.uni-marburg.de

${ }^{b}$ Philipps-Universität Marburg, Hans-Meerwein-Strasse 4, 35043 Marburg, Germany $\dagger$ Electronic supplementary information (ESI) available: Experimental details and analytical data. CCDC 1450140. For ESI and crystallographic data in CIF or other electronic format see DOI: 10.1039/c6cc00972g
}

Using ammonium formate as the hydrogen source, the rhodium complex $\Lambda$-RhO $(1 \mathrm{~mol} \%)$ catalyzed the reduction of acetophenone only sluggishly, providing just $16 \%$ conversion and $69 \%$ ee after 24 hours at $60{ }^{\circ} \mathrm{C}$, whereas the higher

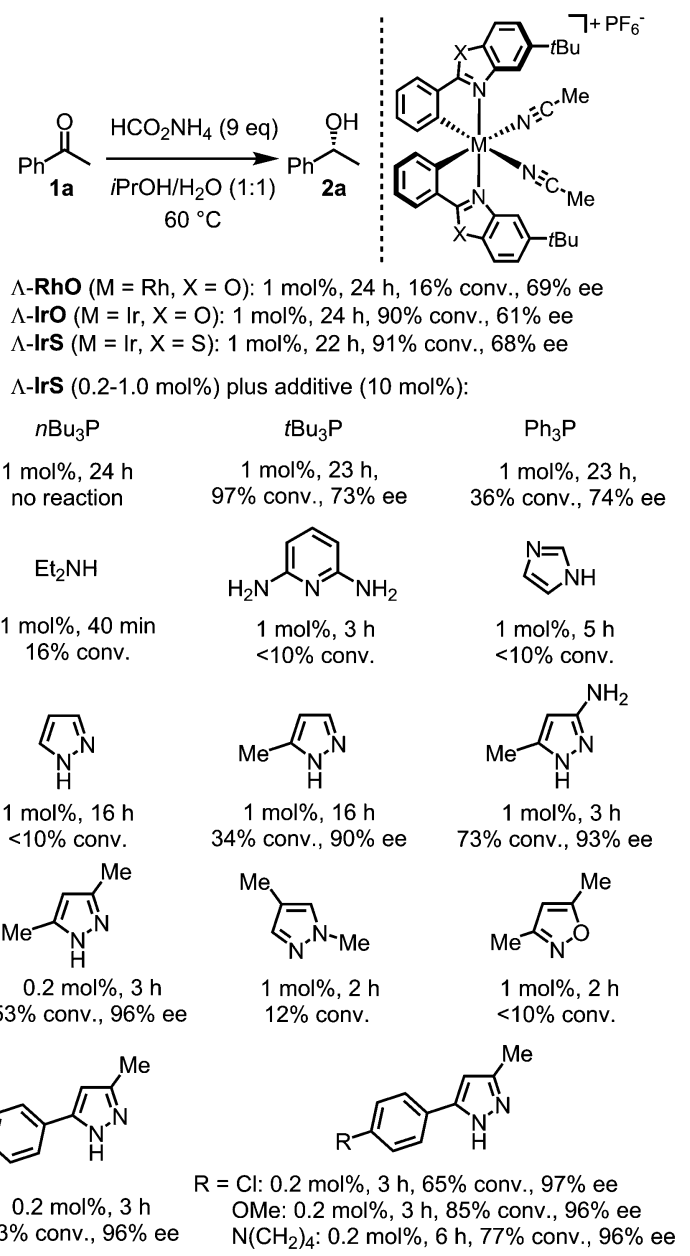

Fig. 1 Initial experiments and screening of ligand additives. Conversion determined by ${ }^{1} \mathrm{H}-\mathrm{NMR}$ and enantioselectivity by HPLC on a chiral stationary phase. 
congener $\Lambda$-IrO (1 mol\%) gave better results with $90 \%$ conversion after 24 hours and $61 \%$ ee. Replacing the benzoxazole ligands $(\Lambda$-IrO) against benzothiazole $(\Lambda$-IrS) further improved the outcome reaching $91 \%$ conversion after 22 hours with $68 \%$ ee. We therefore chose $\Lambda$-IrS as the catalyst of choice and next investigated the effect of additional monodentate ligands on the catalysis. The results are shown in Fig. 1. Whereas some ligands such as $n \mathrm{Bu}_{3} \mathrm{P}, 2$,6-diaminopyridine or imidazole suppressed the catalytic activity, others such as $t \mathrm{Bu}_{3} \mathrm{P}$ resulted in a slight improvement of the enantioselectivity. To our delight, 3,5-dimethylpyrazole markedly improved the catalytic activity and enantioselectivity. With a reduced catalyst loading of just $0.2 \mathrm{~mol} \%, 3$ hours reaction time resulted in a conversion of $53 \%$ with $96 \%$ ee. Replacing the methyl group at the 5-position with a phenyl moiety further improved the results with the best compromise out of reaction rate and enantioselectivity achieved with 5-(4-methoxyphenyl)3-methyl-1 $H$-pyrazole.

We used the combination of $\Lambda$-IrS $(0.2-1.0 \mathrm{~mol} \%)$ and the best pyrazole additive ( $10 \mathrm{~mol} \%$ ) for investigating the substrate scope $(\mathbf{1 a}-\mathbf{x})$ under optimized conditions in $\mathrm{THF} / \mathrm{H}_{2} \mathrm{O}(1: 1)$ as the solvent. Fig. 2 reveals that the ATH reaction of acetophenones with electron donating or withdrawing substitutents within the phenyl moiety provided both high yields and good enantioselectivities (products $\mathbf{2 a}-\mathbf{d}, \mathbf{f}, \mathbf{g}$ ) with an exception of the ortho-methyl substituted substrate (product 2e, 51\% ee). Typically, electron withdrawing groups were slightly less beneficial with regard to enantioselectivity, which might be due to some contribution from uncatalyzed background reaction. Other aromatic ketones containing a naphthyl moiety (product $\mathbf{2 h}$ ), heteroaromatic ring

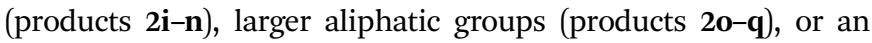
additional ester functionality (product $2 \mathbf{r}$ ), as well as a cyclic ketone (product 2s) were all well converted. Diaryl ketones also provided satisfactory results (products 2t,u). As for dialkyl ketones bearing two primary alkyl chains, for example affording the alcohols $2 \mathbf{v}$ and $2 \mathbf{w}$, high yields (90-94\%) while low ee values ( $9 \%$ and $30 \%$ ee, respectively) were achieved. However, a substrate with one bulky secondary alkyl substituent afforded the desired alcohol 2x with 93\% yield and 94\% ee within 15 hours, suggesting that aliphatic ketones could also work nicely for selected cases. In addition, it is worth to mention that the reaction can be scaled up. For example, $1.0 \mathrm{~g}$ of phenyl(o-tolyl)methanone produced $1.0 \mathrm{~g}$ of its corresponding alcohol $2 \mathrm{t}$ (yield $99 \%$ ) with $97 \%$ ee in presence of $0.5 \mathrm{~mol} \%$ catalyst.

Next, we chose 2-acetyl benzothiophene for testing catalytic performance of the $\Lambda$-IrS/monodentate pyrazole system at lower catalyst loadings $(\mathbf{1 n} \rightarrow \mathbf{2 n})$. As illustrated in Table 1 , the catalyst loading could be reduced to $0.005 \mathrm{~mol} \%(\mathrm{~S} / \mathrm{C}=20000)$ while still keeping a satisfactory reaction time of 108 hours for complete conversion at $60{ }^{\circ} \mathrm{C}$ without affecting the enantioselectivity (entries 1-5). A further reduction to $0.002 \mathrm{~mol} \%$ catalyst led to a slight drop in enantioselectivity value $(96.6 \%$ ee) while a significantly lower reaction rate prevented full conversion (entry 6).

Mechanistically, we propose that the precatalyst $\Lambda$-IrS bearing labile acetonitriles undergoes fast ligand exchange with one pyrazole molecule, followed by reaction with ammonium formate to generate an active iridium hydride species. With assistance of
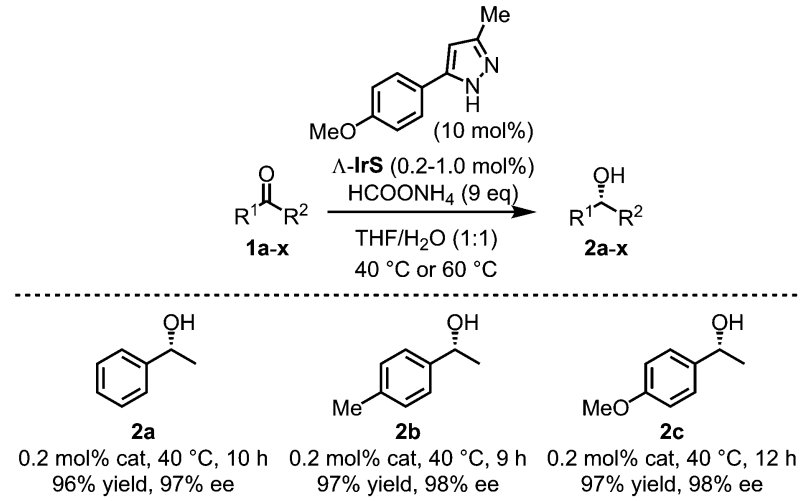

$96 \%$ yield, $97 \%$ ee $\quad 97 \%$ yield, $98 \%$ ee $\quad 97 \%$ yield, $98 \%$ ee

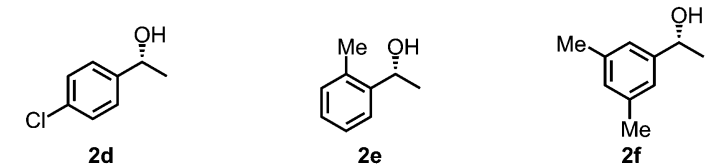

$0.2 \mathrm{~mol} \%$ cat, $40^{\circ} \mathrm{C}, 8 \mathrm{~h} \quad 0.2 \mathrm{~mol} \%$ cat, $40^{\circ} \mathrm{C}, 36 \mathrm{~h} \quad 0.2 \mathrm{~mol} \%$ cat, $40^{\circ} \mathrm{C}, 8 \mathrm{~h}$ $99 \%$ yield, $97 \%$ ee $\quad 95 \%$ yield, $51 \%$ ee $\quad 95 \%$ yield, $97 \%$ ee

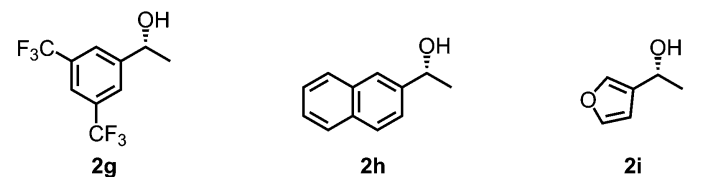

$0.2 \mathrm{~mol} \%$ cat, $40{ }^{\circ} \mathrm{C}, 10 \mathrm{~h} \quad 0.2 \mathrm{~mol} \%$ cat, $40{ }^{\circ} \mathrm{C}, 10 \mathrm{~h} \quad 0.2 \mathrm{~mol} \%$ cat, $40{ }^{\circ} \mathrm{C}, 9 \mathrm{~h}$ $94 \%$ yield, $90 \%$ ee $\quad 99 \%$ yield, $97 \%$ ee $\quad 95 \%$ yield, $96 \%$ ee

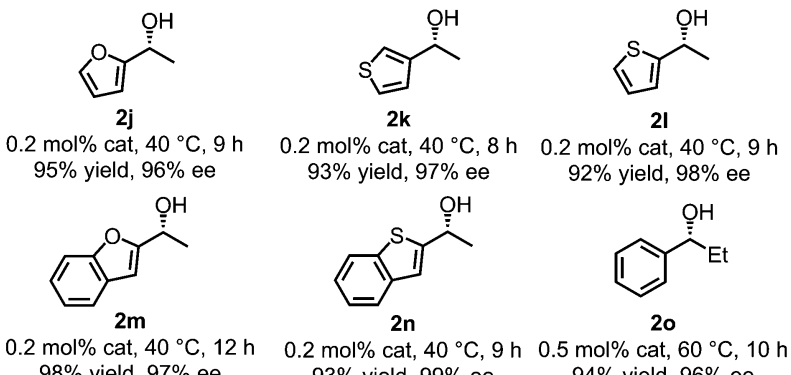
$98 \%$ yield, $97 \%$ ee $\quad 93 \%$ yield, $99 \%$ ee $\quad 94 \%$ yield, $96 \%$ ee

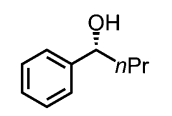

$2 p$

$0.2 \mathrm{~mol} \%$ cat, $40{ }^{\circ} \mathrm{C}, 15 \mathrm{~h} \quad 1.0$ $93 \%$ yield, $97 \%$ ee

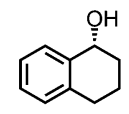
$95 \%$ yield, $98 \%$ ee

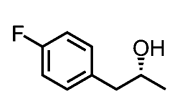

2v

$0.2 \mathrm{~mol} \%$ cat, $40{ }^{\circ} \mathrm{C}, 10 \mathrm{~h}$ $94 \%$ yield, $9 \%$ ee
$0.2 \mathrm{~mol} \%$ cat, $40{ }^{\circ} \mathrm{C}, 18 \mathrm{~h}$

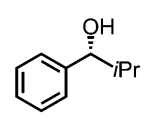

$2 q$

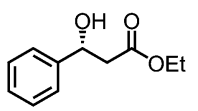

$2 \mathrm{r}$ $0 \mathrm{~mol} \%$ cat, $60{ }^{\circ} \mathrm{C}, 18 \mathrm{~h} \quad 0.2 \mathrm{~mol} \%$ cat, $40{ }^{\circ} \mathrm{C}, 12 \mathrm{~h}$ $91 \%$ yield, $90 \%$ ee $\quad 97 \%$ yield, $96 \%$ ee

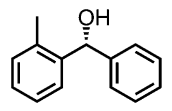

$0.5 \mathrm{~mol} \%$ cat, $40{ }^{\circ} \mathrm{C}, 24 \mathrm{~h} \quad 0.2 \mathrm{~mol} \%$ cat, $40{ }^{\circ} \mathrm{C}, 24 \mathrm{~h}$ $99 \%$ yield, $97 \%$ ee $\quad 97 \%$ yield, $81 \%$ ee

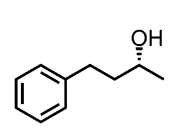

$2 w$

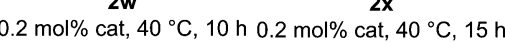

$90 \%$ yield, $30 \%$ ee

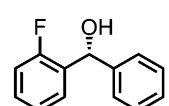

(4)

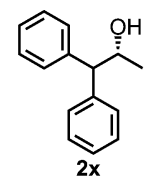

$93 \%$ yield, $94 \%$ ee
Fig. 2 Substrate scope with prochiral ketones.

the ancillary pyrazole ligand, the subsequent concerted transfer of a hydride to the carbonyl carbon and a proton to the carbonyl oxygen leads to formation of the chiral secondary alcohol. The effective asymmetric induction can be explained by less steric 
Table 1 Asymmetric transfer hydrogenation with 2-acetyl benzothiophene ${ }^{a}$

\begin{tabular}{llllll}
\hline & & \\
\hline
\end{tabular}

${ }^{a}$ Reaction conditions: A mixture of $\Lambda$-IrS $(0.002-0.2 \mathrm{~mol} \%)$, 5-(4-methoxyphenyl)-3-methyl- $1 H$-pyrazole $(0.066 \mathrm{mmol})$, and $\mathrm{HCOONH}_{4}(6.0 \mathrm{mmol})$ in $\mathrm{THF} / \mathrm{H}_{2} \mathrm{O}(1: 1)(0.67 \mathrm{~mL})$ was stirred at room temperature for $10 \mathrm{~min}$ before the substrate 2-acetyl benzothiophene $(0.66 \mathrm{mmol})$ was added and the solution stirred at 40 or $60{ }^{\circ} \mathrm{C}$ for the indicated time. ${ }^{b}$ Conversion determined by ${ }^{1}$ H-NMR. ${ }^{c}$ Enantioselectivity by HPLC on a chiral stationary phase. ${ }^{d}$ Values in bracket for a reaction time of 240 hours.

hindrance in the favored transition state as well as additional $\pi-\pi$ stacking between the aromatic ring of the substrate and one cyclometalating benzothiazoline moiety of the iridium complex (Fig. 3, left side). The high catalytic efficiency is in parts attributed to the rigid structure of the catalyst and intermediate limiting the degree of conformational flexibility, thereby providing entropic advantages during catalysis. The mechanism is consistent with an observed $R$-configuration of the formed chiral alcohol assigned by comparison of optical rotations with published examples. ${ }^{8 e, 18}$ Additionally, the importance of the ancillary pyrazole ligand with the crucial role of the $\mathrm{N}-\mathrm{H}$ group is supported by the sluggish results achieved with closely related additive ligands which lack this $\mathrm{N}-\mathrm{H}$, such as 1,4-dimethyl- $1 H$-pyrazole or 3,5-dimethylisoxazole (Fig. 1). ${ }^{19}$ A crystal structure of 5-(4-methoxyphenyl)-3-methyl- $1 H$ pyrazole coordinated to the bis-cyclometalated iridium complex confirms that the pyrazole prefers a conformation in which the $\mathrm{N}-\mathrm{H}$ group is in a perfect position for the proposed bifunctional catalysis (Fig. 4). ${ }^{20}$

In conclusion, we here reported a highly efficient asymmetric transfer hydrogenation for ketones catalyzed by a bis-cyclometalated
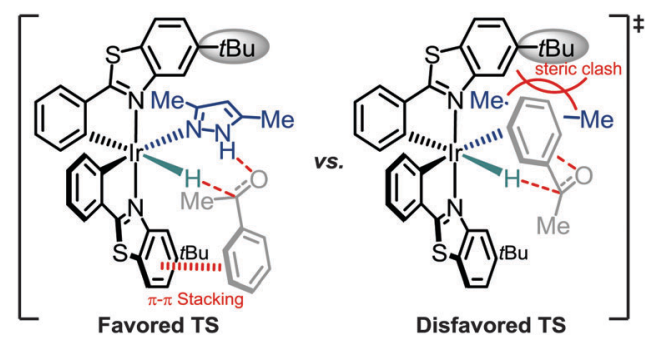

Fig. 3 Proposed transition states through the association of the substrate with a pyrazole-coordinated iridium hydride intermediate explaining the observed enantioselectivities.

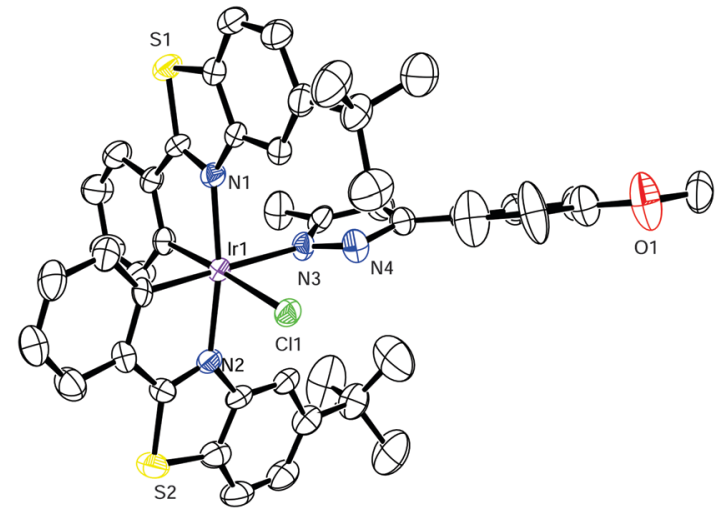

Fig. 4 Crystal structure of an iridium chlorido complex with coordinated pyrazole ligand. ORTEP drawings with $50 \%$ thermal ellipsoids. The complex was crystallized as a racemate but only the $\Lambda$-enantiomer is shown.

chiral-at-metal iridium(III) complex in the presence of an additional pyrazole ligand. The reaction is proposed to proceed through an iridium-hydride intermediate exploiting metalligand cooperativity involving the coordinated pyrazole ligand. A variety of aryl ketones and even one aliphatic ketone are well tolerated in the ATH reaction by affording the secondary alcohols with good to excellent enantioselectivities at catalyst loadings down to $0.002 \mathrm{~mol} \%$. Applications to other substrate classes such as imines are ongoing in our laboratory.

We thank the National Natural Science Foundation of P. R. China (grant no. 21272192, 21472154 and 21572184), the Program for Changjiang Scholars and Innovative Research Team of P. R. China (PCSIRT), the National Thousand Talents Program of P. R. China, the Fundamental Research Funds for the Central Universities (grant no. 20720160027), and the 985 Program of the Chemistry and Chemical Engineering disciplines of Xiamen University.

\section{Notes and references}

¥ Catalysis on gram-scale: To a biphasic solution of 5-(4-methoxyphenyl)-3-methyl- $1 H$-pyrazole $(95.9 \mathrm{mg}, 0.51 \mathrm{mmol})$ and $\mathrm{HCOONH}_{4}$ $(2.89 \mathrm{~g}, 45.9 \mathrm{mmol})$ in $\mathrm{THF} / \mathrm{H}_{2} \mathrm{O}(2.57 \mathrm{~mL} / 2.57 \mathrm{~mL})$ was added the metal catalyst $\Lambda$-IrS $(24.3 \mathrm{mg}, 0.026 \mathrm{mmol})$ in a brown glass vial. The mixture was stirred for $10 \mathrm{~min}$ at room temperature, then phenyl(o-tolyl)methanone $(\mathbf{1 t}, 1.00 \mathrm{~g}, 5.10 \mathrm{mmol})$ was added. The reaction solution was stirred at $40{ }^{\circ} \mathrm{C}$ for $30 \mathrm{~h}$, cooled down to room temperature and then dried under high vacuum. The residue was purified by flash chromatography on silica gel ( $n$-hexane/dichloromethane $=1: 1$ to $1: 2)$ to afford product $2 \mathrm{t}$ as a yellow solid $(0.999 \mathrm{~g}, 5.07 \mathrm{mmol}$, yield: $99 \%)$. Enantiomeric excess of $97 \%$ ee was established by HPLC analysis (Chiralpak OJ column, $250 \times 4.6 \mathrm{~mm}$, absorbance at $220 \mathrm{~nm}, n$-hexane/

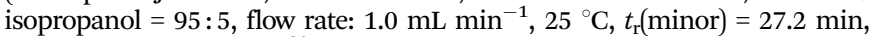
$t_{\mathrm{r}}($ major $\left.)=30.8 \mathrm{~min}\right) \cdot[\alpha]_{\mathrm{D}}^{20}=+6.8\left(c 1.0, \mathrm{CHCl}_{3}\right)$.

1 For selected recent reviews on asymmetric transfer hydrogenation of ketones, see: (a) S. Gladiali and E. Alberico, Chem. Soc. Rev., 2006, 35, 226-236; (b) X. Wu and J. Xiao, Chem. Commun., 2007, 2449-2466; (c) X. Wu, C. Wang and J. Xiao, Platinum Met. Rev., 2010, 54, 3-19; (d) R. Malacea, R. Poli and E. Manoury, Coord. Chem. Rev., 2010, 254, 729-752; (e) A. Bartoszewicz, N. Ahlsten and B. Martin-Matute, Chem. - Eur. J., 2013, 19, 7274-7302; $(f)$ J. Ito and H. Nishiyama, Tetrahedron Lett., 2014, 55, 3133-3146; (g) P. E. Sues, K. Z. Demmans and R. H. Morris, Dalton Trans., 2014, 43, 7650-7667; (h) J. Václavík, P. Sot, J. Pecháček, B. Vilhanová, O. Matuška, M. Kuzma and P. Kačer, Molecules, 2014, 19, 6987-7007; 
(i) Y.-Y. Li, S.-L. Yu, W.-Y. Shen and J.-X. Gao, Acc. Chem. Res., 2015, 48, 2587-2598.

2 S. Hashiguchi, A. Fujii, J. Takehara, T. Ikariya and R. Noyori, J. Am. Chem. Soc., 1995, 117, 7562-7563.

3 For selected examples of ruthenium(II) catalyzed ATH reactions, see: (a) T. Cheng, Q. Ye, Q. Zhao and G. Liu, Org. Lett., 2015, 17, 4972-4975; (b) T. Slagbrand, T. Kivijārvi and H. Adolfsson, ChemCatChem, 2015, 7, 3445-3449; (c) A. Kišić, M. Stephan and B. Mohar, Adv. Synth. Catal., 2015, 357, 2540-2546; (d) R. Soni, T. H. Hall, B. P. Mitchell, M. R. Owen and M. Wills, J. Org. Chem., 2015, 80, 6784-6793; (e) Z. Xu, Y. Li, J. Liu, N. Wu, K. Li, S. Zhu, R. Zhang and Y. Liu, Org. Biomol. Chem., 2015, 13, 7513-7516; $(f)$ C. Cesari, A. Cingolani, C. Parise, S. Zacchini, V. Zanotti, M. C. Cassani and R. Mazzoni, RSC Adv., 2015, 5, 94707-94718; (g) A. Matsuoka, C. A. Sandoval, M. Uchiyama, R. Noyori and H. Naka, Chem. - Asian J., 2015, 10, 112-115; (h) C. Kucukturkmen, A. Agac, A. Eren, I. Karakaya, M. Aslantas, O. Celik, S. Ulukanli and S. Karabuga, Catal. Commun., 2016, 74, 122-125.

4 For selected examples of osmium(II) catalyzed ATH reactions, see: (a) D. Carmona, F. J. Lahoz, P. García-Orduña, L. A. Oro, M. P. Lamata and F. Viguri, Organometallics, 2012, 31, 3333-3345; (b) E. Vega, E. Lastra and M. P. Gamasa, Inorg. Chem., 2013, 52, 6193-6198; (c) J. P. C. Coverdale, C. Sanchez-Cano, G. J. Clarkson, R. Soni, M. Wills and P. J. Sadler, Chem. - Eur. J., 2015, 21, 8043-8046; (d) A. Bolje, S. Hohloch, M. van der Meer, J. Kosmrlj and B. Sarkar, Chem. - Eur. J., 2015, 21, 6756-6764.

5 For selected examples of iridium(III) catalyzed ATH reactions, see: (a) D. Zerla, G. Facchetti, M. Fusè, M. Pellizzoni, C. Castellano, E. Cesarotti, R. Gandolfi and I. Rimoldi, Tetrahedron: Asymmetry, 2014, 25, 1031-1037; (b) D. M. Morris, M. McGeagh, D. De Peña and J. S. Merola, Polyhedron, 2014, 84, 120-135; (c) K. Yoshida, T. Kamimura, H. Kuwabara and A. Yanagisawa, Chem. Commun., 2015, 51, 15442-15445; (d) A. Matsunami, Y. Kayaki and T. Ikariya, Chem. - Eur. J., 2015, 21, 13513-13517; (e) B. Ak, M. Aydemir, F. Durap, N. Meriç, D. Elma and A. Baysal, Tetrahedron: Asymmetry, 2015, 26, 1307-1313; $(f)$ Z.-Q. Rong, Y. Zhang, R. H. B. Chua, H.-J. Pan and Y. Zhao, J. Am. Chem. Soc., 2015, 137, 4944-4947; $(g)$ J. M. M. Verkade, P. J. L. M. Quaedflieg, G. K. M. Verzijl, L. Lefort, F. L. van Delft, J. G. de Vries and F. P. J. T. Rutjes, Chem. Commun., 2015, 51, 14462-14464; (h) W.-P. Liu, M.-L. Yuan, X.-H. Yang, K. Li, J.-H. Xie and Q.-L. Zhou, Chem. Commun., 2015, 51, 6123-6125.

6 For selected examples of rhodium(III) catalyzed ATH reactions, see: (a) L. Zhang, R. Qiu, X. Xue, Y. Pan, C. Xu, H. Li and L. Xu, Adv. Synth. Catal., 2015, 357, 3529-3537; (b) K. Farrell, H. Müller-Bunz and M. Albrecht, Organometallics, 2015, 34, 5723-5733; (c) J. Lu, J. Dimroth and M. Weck, J. Am. Chem. Soc., 2015, 137, 12984-12989; (d) P.-G. Echeverria, C. Férard, P. Phansavath and V. Ratovelomanana-Vidal, Catal. Commun., 2015, 62, 95-99; (e) Z. Lin, J. Li, Q. Huang, Q. Huang, Q. Wang, L. Tang, D. Gong, J. Yang, J. Zhu and J. Deng, J. Org. Chem., 2015, 80, 4419-4429; $(f)$ V. S. Shende, S. H. Deshpande, S. K. Shingote, A. Joseph and A. A. Kelkar, Org. Lett., 2015, 17, 2878-2881.
7 For selected examples of iron(II) catalyzed ATH reactions, see: (a) W. Zuo, A. J. Lough, Y. F. Li and R. H. Morris, Science, 2013, 342, 1080-1083; (b) R. Bigler and A. Mezzetti, Org. Lett., 2014, 16, 6460-6463; (c) W. Zuo, S. Tauer, D. E. Prokopchuk and R. H. Morris, Organometallics, 2014, 33, 5791-5801; (d) S. A. M. Smith and R. H. Morris, Synthesis, 2015, 1775-1779; (e) R. Bigler, R. Huber and A. Mezzetti, Angew. Chem., Int. Ed., 2015, 54, 5171-5174; $(f)$ W. Zuo and R. H. Morris, Nat. Protoc., 2015, 10, 241-257.

8 For selected examples of ATH reactions catalyzed by other transition metals, see: (a) K. Saito, Y. Kajiwara and T. Akiyama, Angew. Chem., Int. Ed., 2013, 52, 13284-13288; (b) P. Clavero, A. Grabulosa, M. FontBardia and G. Muller, J. Mol. Catal. A: Chem., 2014, 391, 183-190; (c) S. Guo, P. Yang and J. Zhou, Chem. Commun., 2015, 51, 12115-12117; (d) H. Xu, P. Yang, P. Chuanprasit, H. Hirao and J. Zhou, Angew. Chem., Int. Ed., 2015, 54, 5112-5116; (e) J. Guo, J. Chen and Z. Lu, Chem. Commun., 2015, 51, 5725-5727; $(f)$ A. Keßberg and P. Metz, Angew. Chem., Int. Ed., 2016, 55, 1160-1163.

9 For reviews covering chiral-at-metal complexes in catalysis, see: (a) H. Brunner, Angew. Chem., Int. Ed., 1999, 38, 1194-1208; (b) P. D. Knight and P. Scott, Coord. Chem. Rev., 2003, 242, 125-143; (c) M. Fontecave, O. Hamelin and S. Ménage, Top. Organomet. Chem., 2005, 15, 271-288; (d) E. B. Bauer, Chem. Soc. Rev., 2012, 41, 3153-3167; (e) L. Gong, L.-A. Chen and E. Meggers, Angew. Chem., Int. Ed., 2014, 53, 10868-10874; $(f)$ Z.-Y. Cao, W. D. G. Brittain, J. S. Fossey and F. Zhou, Catal. Sci. Technol., 2015, 5, 3441-3451.

10 H. Huo, C. Fu, K. Harms and E. Meggers, J. Am. Chem. Soc., 2014, 136, 2990-2993.

11 H. Huo, X. Shen, C. Wang, L. Zhang, P. Röse, L.-A. Chen, K. Harms, M. Marsch, G. Hilt and E. Meggers, Nature, 2014, 515, 100-103.

12 C. Wang, L.-A. Chen, H. Huo, X. Shen, K. Harms, L. Gong and E. Meggers, Chem. Sci., 2015, 6, 1094-1100.

13 C. Wang, Y. Zheng, H. Huo, P. Röse, L. Zhang, K. Harms, G. Hilt and E. Meggers, Chem. - Eur. J., 2015, 21, 7355-7359.

14 X. Shen, H. Huo, C. Wang, B. Zhang, K. Harms and E. Meggers, Chem. - Eur. J., 2015, 21, 9720-9726.

15 Y. Tan, W. Yuan, L. Gong and E. Meggers, Angew. Chem., Int. Ed., 2015, 54, 13045-13048.

16 Y. Huang, L. Song, L. Gong and E. Meggers, Chem. - Asian J., 2015, 10, 2738-2743.

17 C. Wang, J. Qin, X. Shen, R. Riedel, K. Harms and E. Meggers, Angew. Chem., Int. Ed., 2016, 55, 685-688.

18 (a) X. Ren, G. Li, S. Wei and H. Du, Org. Lett., 2015, 17, 990-993; (b) S. Phothongkam and B. Uang, Asian J. Org. Chem., 2015, 4, 794-799; (c) Z. Zuo, L. Zhang, X. Leng and Z. Huang, Chem. Commun., 2015, 51, 5073-5076.

19 The slow conversion in the presence of the sterically less hindered 5-methyl- $1 H$-pyrazole and pyrazole itself can be rationalized with a catalyst deactivation through double coordination.

20 (a) T. Ikariya, K. Murata and R. Noyori, Org. Biomol. Chem., 2006, 4, 393-406; (b) T. Ikariya and A. J. Blacker, Acc. Chem. Res., 2007, 40, $1300-1308$. 